ORIGINAL ARTICLE

\title{
The impact of preoperative body mass index on early complications post laparoscopic sleeve gastrectomy for morbid obesity
}

\author{
Ali Helmy Elshewy I, Tamer Elsaied Alnaimy I, Walid Abdelmawla Aidaros I, Mustafa Saleh \\ Mousbah El-Jadal II
}

\section{I: Department of General Surgery, Faculty of Medicine, Zagazig University, Egypt II: $M B B C H$, Benghazi University, Libya}

\author{
*Corresponding author: \\ Mustafa Saleh Mousbah \\ El-Jadal \\ MBBCH, Benghazi \\ University, Libya \\ Email : \\ mustafaeljadal@gmail.com
}

Submit Date: 2019-03-30

Revise Date: 2019-06-25

Accept Date: 2019-06-27

\begin{abstract}
Background: Morbid obesity is one of the most serious health issues worldwide. The prevalence of morbid obesity has increased over the past two decades at a significant rate in such a way that it can be considered a pandemic. This study is to evaluate the relation between preoperative body mass index (BMI) and early complications post laparoscopic sleeve gastrectomy. Methods: This cohort study had been conducted in Gastrointestinal tract (GIT) and laparoscopic surgical unit in General Surgery Department, Zagazig University Hospitals. after approval from the institutional review board , The study included 15 morbidly obese patients indicated for LSG. Results: This study reported improvement of co-morbidities after 6 months of surgery and few patients developed new onset symptoms of GERD.Complications during surgery and overall complications in ward and after discharge significantly were associated with BMI>50. The BMI $>50$ group was significantly longer in operation time and also longer in hospital stay. Conclusions: Laparoscopic sleeve gastrectomy provides satisfactory weight loss and reduction of BMI with simultaneous im-provement of obesity related co-morbidities
\end{abstract}

Key wards: Morbid obesity, Body Mass, Laparoscopic Sleeve , Gastrectomy

\section{INTRODUCTION}

$\mathrm{O}$ besity is a medical condition in which excess body fat has been accumulated to the extent that it may have an adverse effect on health, leading to reduced life expectancy [1].

The epidemic of obesity has emerged as a major health problem in the world. It is one of the leading preventable causes of death world-wide with increasing prevalence in adults and children. Authorities view it as one of the most serious public health problems of the 21 stcentury[2].

Obesity is calculated as Quetelet's body mass index (BMI) which is the ratio of weight (measured in $\mathrm{kg}$ ) to a height (measured in November. 2020 Volume 26 Issue 6 meters square). Morbid obesity is the harbinger of many diseases that effect essentially every organ system, e.g., cardiovascular, respiratory, metabolic, musculoskeletal, endocrinal reproductive, dermatological, neurological and many more [3].

Bariatric surgery has become the only long-term effective treatment for severe obesity. Caloric restriction, diet, and drug therapy have disappointing results in the longterm weight loss for severe obesity when compared to bariatric surgery[4].

The national institute of health in the United States has recommended bariatric surgery for people who have a BMI > 35 
$\mathrm{kg} / \mathrm{m} 2$ with co-morbidity or BMI $>40 \mathrm{~kg} / \mathrm{m} 2$ [5].

Laparoscopic sleeve gastrectomy (LSG) have become a favored procedure for morbid obesity in the countries due to its cost, safety and effectiveness in weight reduction. Surgical weight loss functions by reducing caloric intake and depending upon the procedure, macronutrients absorption[6].

Laparoscopic Sleeve Gastrectomy (LSG) as a single-stage procedure for the treatment of morbid obesity is becoming increasingly popular[7].

LSG is a simple surgical procedure resulting in low complication rate with insignificant long-term nutritional deficiencies, especially when compared to the other alternative, more aggressive bariatric procedures. Its complications consist mainly of staple-line bleeding, strictures (usually located at the middle or distal portion of the residual stomach), and the most severe, dangerous complication being stapleline leakage[8].

Laparoscopic sleeve gastrectomy was first described as a modification to the biliopancreatic diversion and combined with a duodenal switch in 1998, and was first performed laparoscopically in 1999. Patients experience excellent weight loss after LSG alone, and LSG is considered a single therapy in the treatment of morbid obesity. Weight loss is the most important parameter of bariatric surgery operations, and it is the parameter by which success or failure of weight reducing techniques is measured. Success of treatment has been defined as weight loss $>50 \%$ of excess weight[9].

Assessed the efficacy of LSG in terms of loss of weight and co-morbidity improvement and evaluated the impact of preoperative body mass index (BMI) on the final outcome. BMI is calculated by dividing the weight in kilograms by the square of height in meters $\left[\mathrm{BMI}=\text { weight }(\mathrm{kg}) / \text { height }\left(\mathrm{m}^{2}\right)\right]^{[10]}$. They concluded that laparoscopic sleeve gastrectomy is an efficient treatment to achieve significant weight loss that is maintained up to 5 years of follow up, also it improves some of the obesity related comorbidities. This beneficial impact of LSG appears to be significantly higher in patients with BMI $<50 \mathrm{~kg} / \mathrm{m}^{2}$.

\section{METHODS}

This cohort study had been conducted in Gastrointestinal tract (GIT) and laparoscopic surgical unit in General Surgery Department, Zagazig University Hospitals. The study comprises 15 morbidly obese patients indicated for LSG.

Written informed consent was obtained from all participants and the study was approved by the research ethical committee of faculty of medicine,Zagazig University .The work has been carried out in accordance with the Code of Ethics of the World Medical Association( Declaration of Helsinki) for studies involving humans.

All patients were subjected to full clinical preoperative evaluation as well as investigations. Clinical evaluation aimed at assessment of degree of obesity, preoperative evaluation and detection of different complications of morbid obesity

Age and sex of the patients were recorded. BMI of the patients was calculated as weight (kg), divided by height (m) squared. Thorough clinical evaluation including blood pressure, pulmonary and cardiac examinations was done. All the patients as a part of their routine work up get a full set of labaratory investigations that include a full blood count, lipid profile, plasma glucose level .

\section{Statistical Analysis}

Data collected throughout history, basic clinical examination, laboratory investigations and outcome measures coded, entered and analyzed using Microsoft Excel software. Data were then imported into Statistical Package for the Social Sciences (SPSS version 20.0) (Statistical Package for the Social Sciences) software for analysis. According to the type of data qualitative represent as number and percentage , quantitative continues group represent by mean $\pm S D$, the following tests were used to test differences for significance, difference and association of qualitative variable by $\mathrm{Chi}$ square test $\left(X^{2}\right)$. Differences between quantitative independent groups by $t$ test or Mann Whitney. P value was set at $<0.05$ for significant results $\&<0.001$ for high significant result. 


\section{RESULTS}

Fiftheen patients were included In this study, the mean age was $35.5 \pm 9.5$ with a range ( 24-47 years) for group A and 33.0 \pm 6.7 with a range ( 19-47 years) for group B. Regarding weight, the mean weight was 116.18 \pm 29.7 with a range (104-130.5) for group A, and 166 \pm 25.3 ( 130-183) for group B. Height $161.8 \pm 8.53$ with a range (149-168 $\mathrm{cm}$ ) for group A and 168.9 \pm 8.53 , range ( 160$180 \mathrm{~cm}$ ) for group B . BMI 45.06 \pm 9.17 (37$\left.49.5 \mathrm{~kg} / \mathrm{m}^{2}\right), \quad 58.14 \pm 8.15\left(50.6-70 \mathrm{~kg} / \mathrm{m}^{2}\right)$ for group A and group B respectively and females represented the majority of cases ( 12 patients $80 \%$ ) and only 3 male patients $(20.0 \%)$.

sex as distributed as group A : 1 male patient $(12.5 \%), 7$ female patients $(87.5 \%)$, for group B , 2 male patients(28.6\%) and 5 female patients $(71.4 \%)$.

patients were divided according to their preoperative BMI into two subgroups, group A (BMI less than 50) comprised $8(53.3 \%)$ patients and group B (BMI more than 50)comprised 7 (46.7\%) patients.

Regarding co-morbidities this study showed 2 patients from Group B had DM type II (28.5?\%) and reported no patients from group $\mathrm{A}$, hypertension 1 patient from group A (12.5\%) and 4 patients from group $\mathrm{B}(57.1 \%)$, sleep apnea associated only with group B by 3 patients(42.9?\%) , hyperlipidemia $1(12.5 \%)$ paient from group $\mathrm{A}$ and 2 patients from group $\mathrm{B}(42.9 \%)$, GERD only 1 patient from group $B$ had GERD II (6.7\%) and reported no patients from group A had GERD

the mean operative time for group B was longer than group A, $(90 \pm 15.6$ minutes for group A (range 60-120) and 150 \pm 10.12 minutes for group B (range 120-180 ) .

regarding intra-operative complications among studied groups, difficult port insertion 2 patients(20.0\%) from group B, 1 patient $(6.7 \%)$ from the same group had difficult insufflation while group A went smoothly, liver injury seen in $1(14.3 \%)$ patient from group B due to retractor because liver was fatty and large in 2 patients $(28.6 \%)$ treated conservatively, spleen injury on the other hand seen in 3 patient ( 1 from group $A$ and 2 from group B) because omentum was thick and treated conservatively, which in return led to bleeding more than $200 \mathrm{cc}$, but only 1 (14.3\%) patient from group B needed blood transfusion and and non of the patients required conversion to surgery. At the end of surgery 1 patient from group B had a delayed recovery.

Regarding complications during hospital stay, respiratory complications encountered in 4 patients from group B, deep vein thrombosis occurred in one patient also from group B.

Other complications include post operative nausea and vomiting were the most common in both groups encountered in 7 patients, 3 patients(37.5\%) from group $\mathrm{A}$ and 4 patients from group B (57.1\%).Abdominal pain seen in 5 patients, 2 patients from group A (25.0\%) and 3 patients( $42.9 \%$ ) from group B.

Regarding mean hospital stay was $1.5 \pm 0.81$ ( range 1-2 days) for group $\mathrm{A}$ and $4 \pm 1.56$ ( range 1-7 days) for group B.

During follow up complications like port site infection occurred in 3 patients from group B and one patient died after 2 weeks most probably due to pulmonary embolism.

Table 1. BMI classification distribution:

\begin{tabular}{|l|l|c|c|}
\hline GROUP A & BMI<50 Group & 8 & $\%$ \\
\hline GROUP B & BMI>50 Group & 7 & 53.3 \\
\hline BMI(body mass index) & Total & 15 & 46.7 \\
\hline
\end{tabular}


Table 2. Duration of surgery between studied groups:

\begin{tabular}{|l|c|c|c|c|}
\hline & $\begin{array}{c}\text { Group A } \\
(\mathbf{N}=\mathbf{8})\end{array}$ & $\begin{array}{c}\text { Group B } \\
(\mathbf{N}=7)\end{array}$ & $\mathbf{t}$ & $\mathbf{P}$ \\
\hline $\begin{array}{c}\text { Duration of surgery /m } \\
\text { range }\end{array}$ & $\begin{array}{c}90 \pm 15.6 \\
(60-120)\end{array}$ & $\begin{array}{c}150 \pm 10.12 \\
(120-180)\end{array}$ & 2.295 & 0.03 \\
\hline
\end{tabular}

Table 3. Difficulties and problems during surgery:

\begin{tabular}{|c|c|c|c|c|}
\hline & $\begin{array}{c}\text { Group A } \\
\text { (8) }\end{array}$ & $\begin{array}{c}\text { Group B } \\
(7)\end{array}$ & $\begin{array}{l}\text { total } \\
(15)\end{array}$ & \\
\hline Difficult port insertion & $\begin{array}{c}0 \\
(0.0 \%)\end{array}$ & $\begin{array}{c}3 \\
(42.9 \%)\end{array}$ & $\begin{array}{c}3 \\
(20.0 \%)\end{array}$ & 0.03 \\
\hline Difficult insufflations & $\begin{array}{c}0 \\
(0.0 \%)\end{array}$ & $\begin{array}{c}1 \\
(14.3 \%)\end{array}$ & $\begin{array}{c}1 \\
(6.7 \%)\end{array}$ & 0.99 \\
\hline Fatty and large liver & $\begin{array}{c}0 \\
(0.0 \%)\end{array}$ & $\begin{array}{c}2 \\
(28.6 \%)\end{array}$ & $\begin{array}{c}2 \\
(13.3 \%)\end{array}$ & 0.10 \\
\hline Liver injury & $\begin{array}{c}0 \\
(0.0 \%)\end{array}$ & $\begin{array}{c}1 \\
(14.3 \%)\end{array}$ & $\begin{array}{c}1 \\
(6.7 \%)\end{array}$ & 0.99 \\
\hline Spleen injury & $\begin{array}{c}1 \\
(12.5 \%)\end{array}$ & $\begin{array}{c}2 \\
(28.6 \%)\end{array}$ & $\begin{array}{c}3 \\
(20.0 \%)\end{array}$ & 0.97 \\
\hline Bleeding >200 cc & $\begin{array}{c}1 \\
(12.5 \%)\end{array}$ & $\begin{array}{c}2 \\
(28.6 \%)\end{array}$ & $\begin{array}{c}3 \\
(20 \%)\end{array}$ & 0.97 \\
\hline Need for blood transfusion & $\begin{array}{c}0 \\
(0.0 \%)\end{array}$ & $\begin{array}{c}1 \\
(14.3 \%)\end{array}$ & $\begin{array}{c}1 \\
(6.7 \%)\end{array}$ & 0.99 \\
\hline Difficult recovery & $\begin{array}{c}0 \\
(0.0 \%)\end{array}$ & $\begin{array}{c}1 \\
(14.3 \%)\end{array}$ & $\begin{array}{c}1 \\
(6.7 \%)\end{array}$ & 0.99 \\
\hline
\end{tabular}

Table 4. Complications during hospital stay:

\begin{tabular}{|c|c|c|c|c|c|}
\hline & $\begin{array}{c}\text { Group A } \\
(\mathbf{8})\end{array}$ & $\begin{array}{c}\text { Group B } \\
(\mathbf{7})\end{array}$ & $\begin{array}{c}\text { Total } \\
(\mathbf{1 5})\end{array}$ & & P \\
\hline Nausea and vomiting & 3 & 4 & 7 & 0.45 & 0.98 \\
\hline Abdominal pain & $(37.5)$ & $(57.1 \%)$ & $(46.7 \%)$ & & \\
\hline Chest complications & 2 & 3 & 5 & 0.6 & 0.99 \\
\hline DVT & $(25.0 \%)$ & $(42.9 \%)$ & $(33.3 \%$ & & 0.02 \\
\hline C.V complications & $(0.0 \%)$ & $(57.1 \%)$ & $(26.7 \%)$ & 5.9 & 0.20 \\
\hline & $(0.0 \%)$ & $(14.3 \%)$ & $(6.7 \%)$ & 1.43 & \\
\hline & $(0.0 \%)$ & $(0.0 \%)$ & $(0.0 \%)$ & & \\
\hline
\end{tabular}

Table 5. Duration of Hospital stay distribution between groups:

\begin{tabular}{|l|c|c|c|c|}
\hline & $\begin{array}{c}\text { Group A } \\
(\mathbf{N}=8)\end{array}$ & $\begin{array}{c}\text { Group B } \\
(\mathbf{N}=7)\end{array}$ & $\mathbf{t}$ & $\mathbf{P}$ \\
\hline $\begin{array}{l}\text { Hospital stay/ day } \\
\text { Range }\end{array}$ & $\begin{array}{c}1.5 \pm 0.81 \\
(1-2)\end{array}$ & $\begin{array}{c}2.5 \pm 1.56 \\
(1-4)\end{array}$ & 1.599 & 0.121 \\
\hline
\end{tabular}


Table 6. Complications after discharge (follow up):

\begin{tabular}{|c|c|c|c|c|c|}
\hline & $\begin{array}{c}\text { Group A } \\
(\mathbf{8})\end{array}$ & $\begin{array}{c}\text { Group B } \\
(\mathbf{7})\end{array}$ & $\begin{array}{c}\text { Total } \\
(\mathbf{1 5})\end{array}$ & $\mathrm{x} 2$ & $\mathrm{P}$ \\
\hline $\begin{array}{c}\text { Persistent Nausea and } \\
\text { vomiting }\end{array}$ & 1 & 2 & 3 & & 0.97 \\
\hline Abdominal pain & $(12.5 \%)$ & $(28.6 \%)$ & $(20.0 \%)$ & \\
\hline Surgical site infection & 0 & 1 & 1 & 0.99 \\
\hline Failure of loss of expected & $(0.0 \%)$ & $(14.2 \%)$ & $(6.7 \%)$ & & \\
weight & 0 & 3 & 3 & 4.12 & 0.03 \\
\hline Mortality & $(0.0 \%)$ & $(42.9 \%)$ & $(20.0 \%)$ & & 0.97 \\
\hline & $(12.5 \%)$ & $(28.6 \%)$ & $(20.0 \%)$ & & 0.99 \\
\hline
\end{tabular}

\section{DISCUSSION}

The aim of this study is to evaluate the relation between preoperative body mass index (BMI) and early complications post laparoscopic sleeve gastrectomy.This cohort study had been conducted in Gastrointestinal tract (GIT) and laparoscopic surgical unit in General Surgery Department, Zagazig University Hospitals after approval from the institutional review board . The study comprises 15 morbidly obese patients indicated for LSG.

In this study, patients were divided according to their preoperative BMI into two subgroups, group A (BMI less than 50) comprised $8(53.3 \%)$ patients and group B (BMI more than 50)comprised 7 (46.7\%) patients.

Elbanna et al [11] divided patients according to their preoperative BMI into two subgroups, group I (BMI less than $50 \mathrm{~kg} / \mathrm{m}^{2}$ ) comprised $64(37 \%)$ patients and group II (BMI more than $50 \mathrm{~kg} / \mathrm{m}^{2}$ ) comprised 109 (63\%) patients.

In this study, the mean operative time for group B was longer than group A, $(90 \pm 15.6$ minutes for group A (range 60-120) and $150 \pm 10.12$ minutes for group B(range 120180 ) this seems to be due to fatty and large liver and to thickness of omentum in addition to bleeding that happened during surgey.

There was no big difference between two groups regarding the mean operative time and it was $90.64 \pm 38.3$ and $92.74 \pm 35$ minutes for $<50$ and $>50$ groups respectively in previous study by frezza et al [12].
In this study regarding intra-operative complications among studied groups, 2 patient $(20.0 \%)$ from group B had difficult port insertion and 1 patient $(6.7 \%)$ from the same group had difficult insufflation while group A went smoothly.

Liver injury seen in 1(14.3\%) patient from group B due to retractor because liver was fatty and large in 2 patients $(28.6 \%)$ and it was treated conservatively .

Spleen injury on the other hand seen in 3 patient (1 from group A and 2 from group B) because the omentum was very thick and the dissection of short gastric vessels was difficult. But it was treated conservatively.

Elbanna et al [13] reported that Hemorrhage is one of the most serious and life-threatening complications.the risk of postoperative bleeding has been reported to be between 1 and $6 \%$ after LSG. The source of bleeding can be either intraluminal or extraluminal .

In this study 3 case of intra-operative bleeding more than $200 \mathrm{cc}$ were reported, one patient $(12.5 \%)$ from group A due to spleen injury and oozing fron stableline and was treated conservatively by coagulation and clips applaying and the other 2 patients (28.6\%) from group B due to splenic and liver injury due to retractor and both of them were treated by packing and hemostasis by harmonic scalpel, and non of them required convertion to open surgery and only 1 (14.3\%) patient from group B needed blood transfusion . and at the end of surgery 1 patient from group B had a delayed recovery due to bleeding and respiratory problems and 
she was female $>50 \mathrm{~kg} / \mathrm{m}^{2}$ and she was transferred to ICU.

Fucks et al [14] reported in their study of 135 patients intra-operative bleeding occurred in 10 patients $(7 \%)$ and required suturing, no spleen injury occurred and non of the patients required blood transfusion, stable line test failed in 3 patients.A minor liver injury to the left lobe occurred but did not require any specific treatment.

Braghetto I et al [15] reported Bleeding of short gastric vessels at the upper pole of the spleen occurred in one patient successfully treated with the Ligasure device. Bleeding due to a liver injury caused by the liver retractor was observed in one patient, which was successfully treated with coagulation and hemostatic hydro- soluble mesh.and No conversion to open surgery occurred.

Benotti et al [16] reported, Post operative complications remains to be a matter of concern in those risky patients .High BMI proved to be a major determinat of postoperative complications .

Shauer et al [17] reported Respiratory complications occured with incidence reaching $4.4 \%$ after LSG .

We encountered respiratory complications in this study in 4 patients $(57.1 \%)$ from group B

Brethauer et al [18] reported Deep venous Thrombosis (DVT) is another serious complication with significant mortality, if complicated by pulmonary embolism, with an incidence of $0-1.3 \%$ in large sized studies.

We encounterd only one case $(14.3 \%)$ of DVT in this study from group B complained of pain and swelling in the calf muscle area and the examination revealed tender and swollen calf muscles, the diagnosis confirmed by lower limb Duplex study.the patient started a therapeutic dose of anticoagulant.

Abou Rached et al [19] reported Gastric leak is one of the most serious and dreaded complications of LSG.it occures in up to $5 \%$ of patients following LSG.

This study did not report any leakage from site of anastomosis or intra-abdominal collection in either group .

Elbanna et al [20] reported leakage from the site of anastomosis with intra-abdominal collection in six patients, two patients were treated with ultrasound guided drainage, the other two patients were managed conservatively and the last two patients underwent exploratory laparotomy.

In this study the mean hospital stay was $1.5 \pm 0.81$ ( range 1-2 days) for group $\mathrm{A}$ and $4 \pm 1.56$ ( range 1-7 days) for group $B$.

This longer hospital stay in group B in our study due to complications occurred postoperatively, DVT in one pat

Bamehriz F et al [21] reported mean hospital stay longer than our study, as the mean hospital stay in their study was $3.73 \pm 28.28$ and $4.47 \pm 3.18$ for $<50$ and $>50$ group respectively ient with $\mathrm{BMI}>50 \mathrm{~kg} / \mathrm{m}^{2}$.

Silecchia et al [22] reported The overall mortality rate through 30 days after LSG is 0.19 .

There was only one mortality $(6.6 \%)$ in our study from group B due to pulmonary embolism that occurred on the $14^{\text {th }}$ day postoperative.

Elbanna et al [23] reported one postoperative mortality which occurred at the 8th postoperative day in a male patient with BMI $>50$. This mortality was due to massive pulmonary embolism.

Himpen et al [24] reported Gastricesophageal reflux disease remains aconcern after sleeve gastrectomy and the onset of severe refactory GERD after LSG maybe an indication to revise the procedure to gastric bypass.

In this study 1 patient (14.2\%) from group $\mathrm{B}$ had symptoms of GERD preoperatively showed exaggerated symptoms after 6 months, also 3 patients ( 1 from group A $(12.5 \%)$ and 2 patients $(28.6 \%)$ showed new onset symptoms of GERD after 6 months.

In this study 3 patients (42.9\%) from group B showed surgical site infection.

Ruiz-r-trover et al [25] reported in a study included 40 patients with a mean preoperative body mass index (BMI) of $51.2 \pm 7.9 \mathrm{~kg} / \mathrm{m}^{2}$. Surgical site infections appeared in three patients $(7.5 \%)$.

Ochner et al [26] reported The effect of preoperative BMI was apparent, heavier individuals showed lower percentages of initial and excess weight loss, and that this effect was particularly apparent after the 
initial rapid weight loss phase during the first year, when patients with BMI $<50 \mathrm{~kg} / \mathrm{m}^{2}$ continued losing weight, while patients with BMI $\geq 50 \mathrm{~kg} / \mathrm{m}^{2}$ regained significant weight.

In our study 2 patients(28.6\%) from group $\mathrm{B}$ failed to lose the expected weight after 6 months .

Regarding improvement of comorbidities after Laparoscopic sleeve gastrectomy this study reported that 2 patients from group B which had DM type II only one patient showed improvement after 6 months., 1 patient from group $\mathrm{A}$ had Hypertension showed no improvement after 6 months while 3 patients(42.6\%)from Group B had hypertension showed complete improvement after 6 months of follow up.

1 patient $(12.5 \%)$ from group $\mathrm{A}$ and 3 patients $(42.6 \%)$ from group B had hyperlipidemia preoperatively showed improvement after 6 months.

2 patients $(28.6 \%)$ only from group B had fatty liver both showed improvement.

3 patients $(42.6 \%)$ from group B had sleep apnea before surgery showed complete improvement after 6 months.

There was only 1 patient (14.2\%) from Group B had GERD II symptoms before surgery showed exaggeration of existed symptoms.

While 2 patients $(42.2 \%)$ from group B and 1 patient $(12.5 \%)$ from groupA developed new-onset GERD symptoms after 6 months.

Hegazy et al [27] revealed improvement of dyslipidemia in $70 \%$, hypertension in $62 \%$, arthralgia in $77 \%$, ischemic heart diseases in $56 \%$, and sleep apnea in $86 \%$ of patients.

Ochner et al [28] reported significant weight loss and improvement of T2DM, hypertension and dyslipidemia after LSG in 78 patients, but in whose patients with BMI less than $50 \mathrm{~kg} / \mathrm{m}^{2}$.

When comparing between group with BMI $>50$ and group with BMI $<50 \mathrm{~kg} / \mathrm{m}^{2}$, age was distributed as $30.71 \pm 9.5$ and $35.0 \pm 6.7$ between group with BMI $>50 \mathrm{~kg} / \mathrm{m}^{2}$ and below $50 \mathrm{~kg} / \mathrm{m}^{2}$ respectively. Sleep apnea was significantly associated with group with BMI $>50 \mathrm{~kg} / \mathrm{m}^{2}$. Complications during surgery and overall complications in ward and after discharge significantly were associated with
BMI $>50 \mathrm{~kg} / \mathrm{m}^{2}$. and longer in operation time and also longer in hospital stay.

\section{CONCLUSION}

Complications during surgery and overall complications in ward and after discharge significantly were associated with BMI $>50$. The BMI >50 group was significantly longer in operation time and also longer in hospital stay.

Conflict of interest: Nothing to declare. Financial Disclosure: Nothing to declare. REFERENCES

1- Dorian R. Anaesthesia of the surgical patient. In: Schwartz's principles of Surgery $9^{\text {th }}$ edition. Edited by, Brunicardi FC, Andersen DK, Billiar TR, Dunn DL, Hunter JG and Pollock RE. Publishe by, The McGrawHill Companies, New York (2010). P 3373-3412.

2- Nocca D, Krawczykowsky D, Bomans B, Noël P, Picot MC, Blanc PM, et al. A prospective multicenter study of 163 sleeve gastrectomies: Results at 1 and 2 years. ObesSurg. 2008; 18: 560-565.

3- Boza C, Salinas J, Salgado N, Pérez G, Raddatz A, Funke R, et al. Laparoscopic sleeve gastrectomy as a stand-alone procedure for morbid obesity: Report of 1,000 cases and 3-year follow-up. ObesSurg. 2012; 22: 866-871.

4- Rucker D, Padwal R, Li S, Curioni C, Lau DC, et al. Long term pharmacotherapy for obesity and overweight: updated meta-analysis. BMJ. 2007; 335: 1194-1199.

5- Prasad P, Tantia O, Patle N, Khanna S, Sen B, et al. An analysis of 1-3-year follow-up results of laparoscopic sleeve gastrectomy: An Indian perspective. Obes Surg. 2012; 22: 507-514.

6- Arias E, Martínez PR, Ka Ming Li V, Szomstein S, Rosenthal RJ et al. Mid-term follow-up after sleeve gastrectomy as a final approach for morbid obesity. ObesSurg.2009; 19: 544-548.

7- Rubino F, Goncalves C, Brethauer S, and Schauer $\mathbf{P}$ et al. Physiology and Metabolism in Obesity Surgery: Roux-en-Y Gastric Bypass. In: Obesity Surgery Principles and Practice. Editors, Edited by, Pitombo C, Jones K, Higa K, and Pareja J. Published by, The McGraw-Hill Companies, New York. 2008. P: 106114.

8- Csendes A, Braghetto I, Leon P, Burgos A M, et al. Management of leaks after laparoscopic sleeve gastrectomy in patients with obesity. Journal of Gastrointestinal Surgery. 2010; 14(9): 1343-1348.

9- Shi X, Karmali S, Sharma AM, Birch DW, et al. A review of laparoscopic sleeve gastrectomy for morbid obesity. ObesSurg. 2010; 20: 1171-1177.

10- Elbanna H, Ghnnam W, Negm A, Youssef T, Emile S, El Metwally T, et al. Impact of preoperative body mass index on the final outcome after laparoscopic sleeve gastrectomy for morbid obesity. Ulus Cerrahi Derg. 2012; 32: 238-243.

11- Bamehriz F, Athuwaini S, Alobaid O, Alanazi $\mathbf{Y}$, Alotaibi R, Alfuweres $\mathbf{N}$, et al. Is body mass index $\geq 50 \mathrm{~kg} / \mathrm{m}^{2}$ a predictor for high morbidy for patients 
who have undergone laparoscopic sleeve gastrectomy.Saudi journal of Karen Basen-Engquist \& Maria Chang anesthesia. 2018; 12(4): 555-558.

12- Frezza EE. Laparoscopic vertical sleeve gastrectomy for morbid obesity : the future of choice? Surg.today. 2007; (37): 275-281.

13-- Elbanna H, Ghnnam W, Negm A, Youssef T, Emile S, El Metwally T, et al. Impact of preoperative body mass index on the final outcome after laparoscopic sleeve gastrectomy for morbid obesity. UlusCerrahiDerg. 2016; 32: 238-243.

14- Fuks D, Verhaeghe P, Brehant O, Sabbagh C, Dumont F, Riboulot $M$, et al. Results of laparoscopic sleeve gastrectomy: a prospective study in 135 patients with morbid obesity. Surgery. 2009; 145(1): 106-113.

15- Braghetto I, Korn O, Valladares H, Gutiérrez L, Csendes A, Debandi A, et al . Laparoscopic sleeve gastrectomy ,surgical technique, indication and clinical results Obes.Surg. 2007; 17(11):1442-50.

16- Benotti P, Wood GC, Winegar DA, Petrick AT, Still CD, Argyropoulos G, et al . mortality after Roux-en-Y gastric bypass surgery .Ann Surg. 2013; 10: 1097.

17- Schauer P, Ikramuddin S, Gourash W, , Ramanathan R, , and Luketich J, et al. Outcomes of laparoscopic gastric by-pass for morbid obesity;Ann Surg. 2000; 515-529.

18- Brethauer S, Chand B,and Shauer PR ., et al . Risks and benefits of bariatric surgery; cleve cline JMed. 2007; 73(11): 993-1007.

19- Abou Rached A, Basile M, El Masri H,et al. Gastric leaks post sleeve gastrectomy: Review of its prevention and management. World J Gastroenterol. 2014; 20: 13904-13910.

20- Elbanna H, Ghnnam W, Negm A, Youssef T, Emile S, El Metwally T, et al. Impact of preoperative body mass index on the final outcome after laparoscopic sleeve gastrectomy for morbid obesity. Ulus Cerrahi Derg. 2016; 32: 238-243.

21-- Bamehriz F, Althuwaini S, Alobaid O, Alanazi $\mathbf{Y}$, Alotaibi R, Alfuweres $\mathbf{N}$, et al. Is body mass index $\geq 50 \mathrm{~kg} / \mathrm{m}^{2}$ a predictor for high morbidy for patients who have undergone laparoscopic sleeve gastrectomy. Saudi journal of Karen Basen-Engquist \& Maria Chang anesthesia. 2018; 12(4): 555-558.

22-Silecchia G, Boru C, Pecchia A, Rizzello M, Casella G, Leonetti F, et al. Effectiveness of laparoscopic sleeve gastrectomy (first stage of biliopancreatic diversion with duodenal switch) on co-morbidities in super-obese highrisk patients. Obes Surg. 2006;16:1138-44.

23- Elbanna H, Ghnnam W, Negm A, Youssef T, Emile S, El Metwally T, et al. Impact of preoperative body mass index on the final outcome after laparoscopic sleeve gastrectomy for morbid obesity. UlusCerrahiDerg. 2016; 32: 238-243.

24- Himpens J , Dapri G, Bernard G, et al. A respective randomized study between Gastric banding and laparoscopic sleeve gastrectomy. Obesity Surgery. 2006; 1450-1456.

25- Ruiz-Tovar J, Oller I, Llavero C. Pre-operative or early post-operative factors associated with surgical site infection .after laparoscopic sleeve gastrectomy... Surg Infect (Larchmt). 2013;14(4):369-73.

26- Ochner CN, Jochner MC, Caruso EA, Teixeira J, Xavier Pi-Sunyer F, et al. Effect of preoperative body mass index on weight loss after obesity surgery. Surg Obes Relat Dis. 2013; 9: 423-427.

27- Hegazy TO, Ewis AA . Glycemic changes after sleeve gastrectomy in type 2 diabetic morbidly obese patients. Edorium J Surg. 2014; 1: 1-9.

28- Ochner CN, Jochner MC, Caruso EA, Teixeira J, Xavier Pi-Sunyer F, et al. Effect of preoperative body mass index on weight loss after obesity surgery. Surg Obes Relat Dis. 2013; 9: 423-427.

\section{Cite This Article - VANCOUVER Style}

Eljadal, M., El-Shewy, A., alnaimy, T., aidaros, W. The impact of preoperative body mass index on early complications post laparoscopic sleeve gastrectomy for morbid obesity. Zagazig University Medical Journal, 2020; (892-899): -. doi: 10.21608/zumj.2019.11201.1173 